\title{
TENTATIVA DE DESENVOLVIMENTO DE FORMAS ERITROCITÁRIAS DE PLASMODIUM BRASILIANUM IN VITRO
}

\author{
Salma G. Oliveira 1, Álvaro A. Couto', Marco Antônio V. Santos ${ }^{1}$ Virgilio E. do Rosário²
}

Sabe-se que nem todas as espécies de plasmódios se adaptam às condições de cultivo contínuo in vitro. Na malária humana, por exemplo, o Plasmodium falciparum é a única espécie que apresenta excelente adaptaçâo. Em primatas, resultados satisfatórios foram obtidos em macacos do Velho Mundo, com a adaptação do $P$. inui, $P$. cynomolgi e $P$. fragile ao cultivo in vitro 245.

Recentemente, durante a operação de resgate e salvamento da Usina Hidrelétrica de Tucurui-PA, várias espécies de macacos do Novo Mundo, pertencentes aos gêneros Alouatta, Callicebus, Saimiri, e Saguinus, foram encontrados com infecção natural causada por $P$. brasilianum. Em Saguinus, não havia sido anteriormente detectada infecção natural na América do Sul ${ }^{1}$.

Devido à suscetibilidade do homem aos plasmódios de macacos, demonstrada por meio de infecções experimentais ou, mais raramente, através de infecções naturais ${ }^{3}$, nos propusemos a adaptar o $P$. brasilianum ao cultivo continuo in vitro, objetivando sua posterior caracterização através da análise enzimática, assim como pela diversidade antigênica utilizando-se anticorpos monoclonais, em face da semelhança morfológica e antigênica deste plasmódio com o $P$. malariae, que é uma das espécies causadoras da malária humana.

Três animais da espécie Alouatta belzebul com infecção comprovada através de esfregaço e gota espessa, corados pelo método de Giemsa, foram selecionados no Centro de Triagem instalado na área de enchimento do reservatório da Usina Hidrelétrica de Tucurui, PA, e transferidos para o laboratório do Programa Malária do Instituto Evandro Chagas, em Belém.

Os espécimes foram esplenectomizados a fim de que fosse mantida e conseqüentemente aumentada a parasitemia original.

1. FSESP - Instituto Evandro Chagas, Av. Almirante Barroso $492-66000$ Belém, PA.

2. Atualmente fixado no Biomedical Research Institute Maryland - USA.

Apoio Financeiro: FINEP - Financiadora de Estudos e Projetos e SUCAM - Superintendência de Campanhas de Saúde Pública.

Recebido para publicação em 16/12/85
As amostras utilizadas para a adaptação ao cultivo contínuo foram isoladas no $39 \circ$ dia após a esplectomia, momento em que apresentavam parasitemia em torno de $1 \%$, com parasitas nos estágios de trofozoitas, esquizontes e gametócitos, observandose predominância das formas de trofozoitos jovens.

O sangue infectado foi obtido por punção endovenosa, com seringa heparinizada, posteriormente lavado duas vezes com meio RPMI 1640 (Gibco) sem soro. Às hemácias lavadas foi adicionado o meio completo, RPMI 1640, tamponado com HEPES $25 \mathrm{mM}$ (Sigma) $+\mathrm{NaHCO}_{3}$ a $5 \%$ (Sigma), singlementado com soro humano a $10 \%$ ou com plasma de macaco $A$. belzebul a $10 \%$, enriquecido com insulina $80 \mathrm{U}$ em uma proporção de $0,2 \mathrm{U} / \mathrm{ml}$, obtendo-se uma suspensão final com hematócrito de 5\%. Em seguida, essa suspensão foi distribuída em placas de Petri ( $15 \mathrm{~mm}$ ) e incubadas a $37{ }^{\circ} \mathrm{C}$, de acordo com o método clássico descrito por Trager \& Jensen ${ }^{6}$, utilizando-se o sistema de dessecador com vela para obtenção da tensão de $\mathrm{CO}_{2}$ adequada.

$\mathrm{O}$ meio de cultivo foi substituído duas vezes por dia e em intervalos de 8 horas, esfregaços foram feitos para a observação do desenvolvimento dos parasitos nas condições de cultivo.

Os parasitos cultivados em meio RPMI 1640 suplementado com plasma de $A$. belzebul mostraram melhor aspecto morfológico que os submetidos às mesmas condições, porém, com meio suplementado com soro humano.

Os resultados observados após 96 horas de cultivo contínuo, permitiram acompanhar a evolução dos parasitas do estágio de trofozoito à esquizontes. Contudo, não ocorreu a rotura das hemácias parasitadas com esquizontes maduros, conseqüentemente não houve liberação dos merozoitos para a reinvasão de novos eritrócitos.

Em função do retardamento da rotura das hemácias parasitadas, observou-se crescimento dos merozoitos no interior dos eritrócitos, seguido da interrupção do desenvolvimento dos parasitos.

Os esquizontes nas condições de cultivo, apresentavam-se com 4 a 6 núcleos, enquanto que in vivo apresentavam-se em média com 8 núcleos.

Nossos resultados demonstraram um evidente desenvolvimento dos parasitas da fase de trofozoitos até esquizontes. Entretanto, por razōes ainda não esclarecidas não houve a rotura desses esquizontes, conseqüentemente impedindo a continuidade do ciclo, 
Comunicação. Oliveira SG, Couto AA, Santos MAV, Rosário VE. Tentativa de desenvolvimento de formas eritrocitárias de Plasmodium brasilianum in vitro. Revista da Sociedade Brasileira de Medicina Tropical 20: 45-46, Jan-Mar, 1987.

uma vez que não se deu a reinvasão de novas hemácias pela não liberação de merozoitos.

Acreditamos que, com a continuidade desse trabalho, possivelmente introduzindo-se algumas modificações na metodologia, seja possível a adaptação do $P$. brasilianum em cultivo continuo.

\section{REFERÊNCIAS BIBLIOGRÁFICAS}

1. Arruda ME. Presença do Plasmodium brasilianum em macacos capturados na área de enchimento do reservatório da usina hidrelétrica de Tucurui, Pará. Memórias do Instituto Oswaldo Cruz 80: 367-369, 1985.

2.Collins WE Chin W, Skinner JC. Plasmodium fragile and Macaca mulata monkeys, of a model system for the study of malaria vaccines. American Journal of Tropical Medicine and Hygiene 28:948-954, 1979.

3. Deane LM, Neto JAF, Okumura M, Ferreira MO. Malaria parasites of Brazilian monkeys. Revista do Instituto de Medicina Tropical de São Paulo 11: 7186, 1969.

4. Nguyen-Dinh P, Campbell CC, Collins WE. Cultivation in vitro of the quartan malaria $P$. innui. Science 209:1249-1251, 1980.

5. Nguyen-Dinh P, Gardner AL, Campbell CC, Skinner JC, Collins WE. Cultivation in vitro of the vivax - type malaria parasite $P$. cynomolgi. Science 212:1146-1148, 1981.

6. Trager W, Jensen JB. Human malaria parasites in continuous culture. Science 193:673-675, 1976. 